\title{
SISTEM INFORMASI PEMESANAN KERTAS CONTINUOUS FORM PT. ERAJAYA MANDIRI PRATAMA JAKARTA
}

\author{
Ahmad Fauzi ${ }^{1}$ \\ ${ }^{1}$ Sistem Informasi Akuntansi \\ Universitas Bina Sarana \\ Informatika \\ ahmad.afz@bsi.ac.id
}

\author{
Erniawati $^{2}$ \\ ${ }^{2}$ Sistem Informasi \\ Universitas Bina Sarana \\ Informatika \\ cantikernie@gmail.com
}

\author{
Aziz Setyawan. $\mathbf{H}^{3}$ \\ ${ }^{3}$ Teknologi Komputer \\ Universitas Bina Sarana \\ Informatika \\ aziz.aiz@bsi.ac.id
}

\begin{abstract}
bstrak - Pada penelitian ini dimana ada sebuah perusahaan yang menjual suatu barang dengan menggunakan metode pemesanan yang masih kurang efektif dan efisien serta cenderung dapat menghambat proses transaksi perusahaan tersebut. Dalam menemukan solusi permasalahan demikian penulis membuat suatu metode penelitian. Dengan mengumpulkan data hasil penelitian yang didapatkan. Penulis dapat menganalisa dan berhasil membuat suatu solusi dari permasalahan tersebut, yaitu dengan dibuatkanya suatu sistem pemesanan dimana sistem tersebut adalah berbasis website, yang dapat menjadi media antara pembeli kepada perusahaan tersebut dalam melakukan pemesanan produk. Dalam pembuatan sistem pemesanan ini penulis dapat memecahkan masalah yang sedang dihadapi penulis serta dapat menjadi solusi bagi pembaca untuk masalah yang sama.
\end{abstract}

Kata Kunci : Sistem Informasi, Pemesanan Kertas Cotinuous Form, Aplikasi Berbasis Web

\begin{abstract}
In the study where there is a company that sells an item using the order method that is still less effective and efficient and tend to be able to inhibit the transaction process company. In finding solutions such problems the authors make a research method. By collecting data obtained research results. The author can analyze and successfully create a solution of the problem, that is with the creation of an ordering system where the system is based website, which can be a medium between buyers to the company in ordering products. In making this ordering system the author can solve the problem that is being faced by the author and can be a solution for readers to the same problem.

Keywords: Information System, Booking Continuous Form PT. Erajaya Mandiri Pratama, Application Bassed Web
\end{abstract}

\section{PENDAHULUAN}

Pada suatu sistem pengelolaan data pada perusahaan yang dilakukansecara tidak maksimal maka akan menyebabkan terhambatnya suatu pencapaian targetyang sudah menjadi tujuan utama perusahaan tersebut. Semakin tingginya persaingan mendorong perusahaan untuk menggunakan sebuah sistem informasi.Seperti menurut(Asmani,2011) dalam (Hidayatun, Herlawati dan Frieyadi,2013)mengemukakan bahwa, "Sistem informasi adalah segala cara untuk menyimpan data". Dengan demikian, teknologi informasi mengacu pada teknologi yang digunakan untuk menyimpan data.Dengan adanya kemajuan disemua bidang segala macam cara untuk menyimpan data tersebut bisa dilakukan dengan komputer, atau yang biasa dikenal sebagai komputerisasi. Data adalah istilah yang digunakan untuk menunjukkan angka, huruf, atau tulisan. Sedangkan informasi adalah data yang telah diproses atau diolah. Dalam persaingan dunia bisnisperusahaan dituntut untuk menekan pengeluaran dan meningkatkan pendapatan yang harus dilakukan perusahaan.Salah satunya yaitu dengan melakukan efisiensi sistem pemesanan produk dari pelanggan kepada perusahaan dengan menggunakan suatu sistem informasi pemesanan. Dengan adanya sistem informasi pemesanan ini perusahaan dapat menekan pembiayaan yang keluar atas aktifitas yang seharusnya bisa dilakukan secara efisien dan dapat meningkatkan pendapatan perusahaan serta percepatan transaksi dengan data yang akurat.

\section{METODE PENELITIAN}

Model pengembangan perangkat lunak merupakan salah satu dari tahap rancangan aplikasi yang detail dari siklus hidup pengembangan aplikasi. Menurut (Pressman,2010) dalam (Ramanda,2017) mengemukakan bahwa, "Metode waterfall adalah model klasik yang bersifat sistematis, berurutan dalam membangun software.

Model Waterfall dibagi menjadi beberapa bagian yaitu: 
a. Analisis Kebutuhan Perangkat Lunak

Proses pengumpulan kebutuhan dilakukan secara intensif untuk menspesifikasikan kebutuhan perangkat lunak agar dapat dipahamai perangkat lunak seperti apa yang dibutuhkan oleh user. Spesifikasi kebutuhan perangkat lunak pada tahap ini perlu untuk didokumentasikan.

b. Desain

Desain perangkat lunak adalah proses multi langkah yang fokus pada desain pembuatan program perangka lunak termaksud struktur data, arsitektur perangkat lunak, representasi antarmuka, dan proses pengkodean. Tahap ini menstranslasi kebutuhan perangkat lunak dari tahap analisis kebutuhan ke representasi desain agar dapat diimplementasikan menjadi program pada tahap selanjutnya. Desain perangkat lunak yang dihasilkan pada tahap ini juga perlu didokumentasikan.

c. Pembuatan Kode Program

Desain harus di translasikan ke dalam program perangkat lunak. Hasil dari tahap ini adalah program komputer sesuai dengan desain yang telah dibuat pada tahap desain.

d. Pengujian

Pengujian fokus pada perangkat lunak secara dari segi lojik dan fungsional dan memastikan bahwa semua bagian sudah diuji. Hal ini dilakukan untuk meminimalisir kesalahan (error) dan memastikan keluaran yang dihasilkan sesuai dengan yang diinginkan.

e. Pendukung (Support) atau pemeliharaan (maintenance)

Tidak menutup kemungkinan sebuah perangka lunak mengalami perubahan ketika sudah dikirimkan ke user. Perubahan bisa terjadi karena adanya kesalahan yang muncul dan tidak terdeteksi saat pengujian atau perangkat lunak harus beradaptasi dengan lingkungan baru. Tahap pendukung atau pemeliharaan dapat mengulangi proses pengembangan mulai dari analisis spesifikasi untuk perubahan perangkat lunak yang sudah ada, tapi tidak untuk membuat perangkat lunak baru.

\section{Teori Pendukung}

\section{ERD}

Menurut (Fathansyah,2012) Entity Relationship Diagram (ERD) adalah model entity relationship yang berisi komponen-komponen himpunan entitas dan himpunan relasi yang masing-masing dilengkapi dengan atribut-atribut yang merepresentasikan seluruh fakta dari dunia nyata yang ditinjau sehingga dapat digambarkan dengan lebih sistematis.

Komponen ERD Menurut (Fatta,2007) mengemukakan bahwa, "Didalam ERD terdapat komponen-komponen khusus untuk menggambarkan elemen-elemen ERD. Anatara lain yaitu:

a. Entitas

Entitas adalah objek yang harus menampilkan beberapa kali event untuk menjadi sebuah entitas

b. Atribut

Atribut adalah informasi dari sebuah entitas yang merupakan kata benda dan hanya digunakan oleh organisasi yang dimasukan dalam model.

c. Identifier

Identifier adalah satu atau lebih atribut yang dapat menjadi identifier entitas secara unik mengidentifikasi setiap anggota dari entitas.

d. Kardinalitas

Kardinalitas adalah hubungan antara suatu instance pada entitas dapat berelasi dengan instance lain di instance yang berbeda

e. Modalitas

Modalitas dapat dikatakan suatu instance dari entitas anak dapat ada tanpa suatu relasi dengan instance dari entitas induk atau tidak.

2. ( LRS ) Logical Record Structure

Menurut (Pradani dkk,2013) memberi batasan bahwa, "LRS adalah representasi dari struktur record-record pada tabel-tabel yang terbentuk dari hasil antar himpunan entitas".

3. UML (Unifield Modelling Language)

Menurut (Simaremare Apol dan Radityo,2013) memberi batasan bahwa," UML merupakan bahasa visual dalam pemodelan yang memungkinkan pengembang sistem membuat sebuah blueprint yang dapat menggambarkan visi mereka tentang sebuah sistem dalam format yang standar, mudah dimengerti, dan menyediakan mekanisme untuk mudah dikomunikasikan dengan pihak lain". Berikut ini adalah beberapa jenis UML diagram yang digunakan pada sistem perancangan pemesanan yang penulis gunakan yaitu:

1. Activity Diagram

Menurut (Simaremare Apol dan Radityo,2013) memberikan batasan bahwa," Activity diagram adalah diagram yang menggambarkan sifat dinamis secara alamiah sebuah sistem dalam bentuk model aliran dan kontrol dari aktivitas ke aktivitas lainnya".

2. Use Case Diagram

Menurut (Simaremare Apol dan Radityo,2013) memberi batasan bahwa," 
Usecase adalah suatu pola atau gambaran yang menunjukan kelakukan atau kebiasaan sistem".

3. Class Diagram

Menurut (Henderi dalam Simaremare Pribadi dan Wibowo,2013) mengemukakan bahwa, "Activity diagram adalah diagram yang menggambarkan sifat dinamis secara alamiah sebuah sistem dalam bentuk model aliran dan kontrol dari aktivitas ke aktivitas lainnya".

4. Sequence Diagram

Menurut (Simaremare Pribadi dan Wibowo,2013) memberi batasan bahwa,"Sequence diagram adalah suatu diagram yang memperlihatkan ataumenampilkan interaksi-interaksi antar objek di dalam sistem yang disusun pada sebuah urutan atau rangkaian waktu. Interaksi antar objek tersebut termasuk pengguna, display, dan sebagainya berupa".

\section{PEMBAHASAN}

\subsection{Analisis Kebutuhan}

1. Kebutuhan Pengguna

a. Kebutuhan Bagian Pelanggan

1) Melakukan pemesanan dengan mengisi form

2) Melihat daftar produk

3) Melihat kontak perusahaan

b. Kebutuhan Bagian Marketing

1) Melihat daftar produk

2) Melihat kontak perusahaan

c. Kebutuhan Bagian Owner

1) Mengubah daftar produk

2) Melihat daftar produk

3) Mengubah deskripsi produk

4) Melihat deskripsi kontak perusahaan

d. Kebutuhan Sistem

1) Pengguna harus melakukan login untuk mengakases sistem

2) Pengguna harus melakukan logout setelah selesai mengakses sistem.

3) Sistem secara otomatis menyimpan perubahan data yang terjadi pada saat pengguna membuat, mengubah dan menghapus data.

4) Sistem secara otomatis mengirim email yang berisi data yang telah diisi pada form pemesanan 3.2 Rancangan Diagram UML

\section{Activity Diagram}

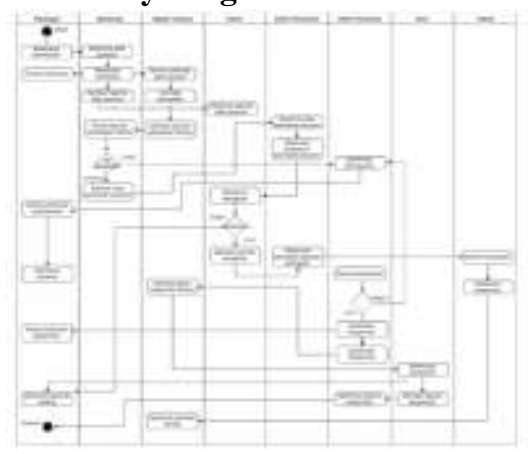

\subsection{ERD}

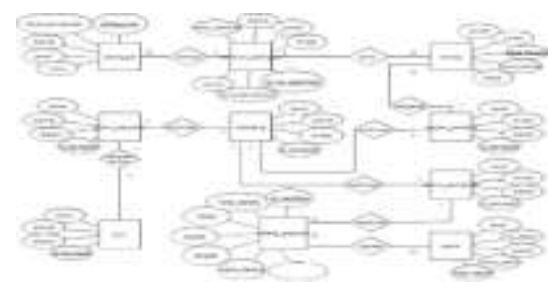

\subsection{LRS}

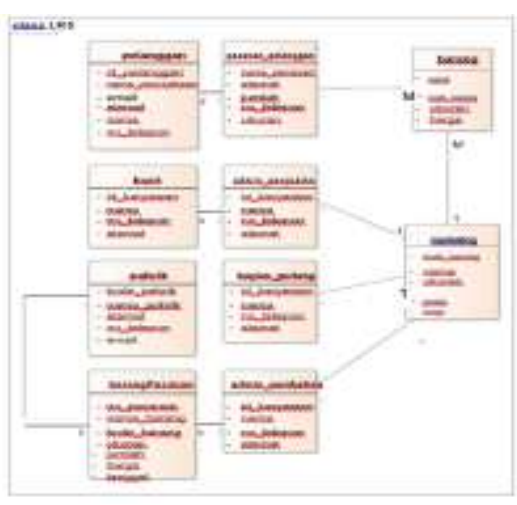

\section{Diagram Use Case}

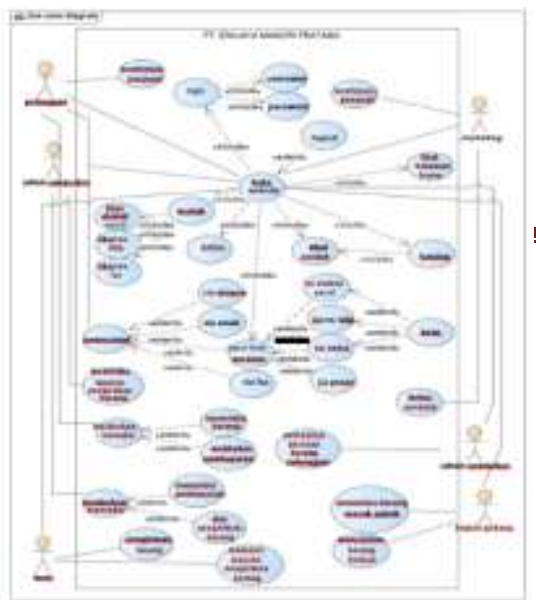




\section{TAMPILAN WEBSITE}

\section{Halaman Index}

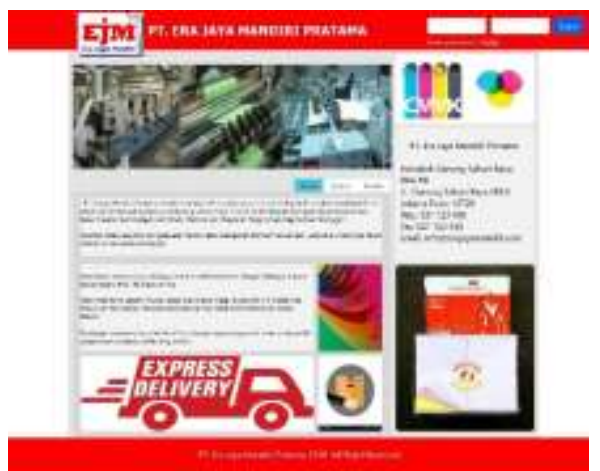

2. Halaman Daftar Member

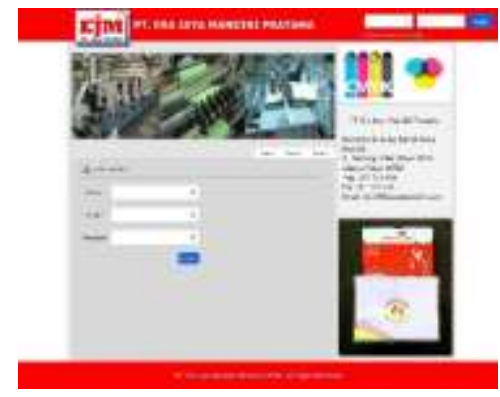

\section{Halaman Menu Produk}

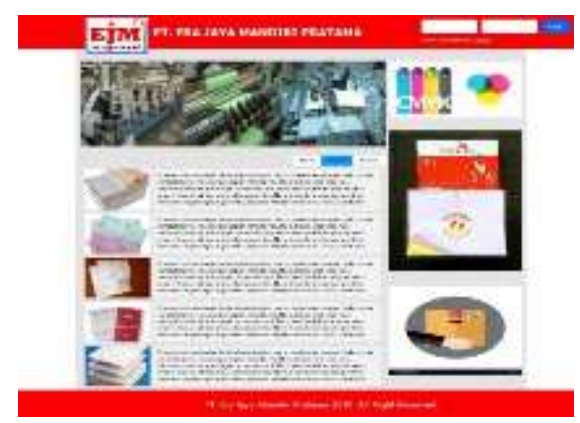

\section{Halaman Kontak}

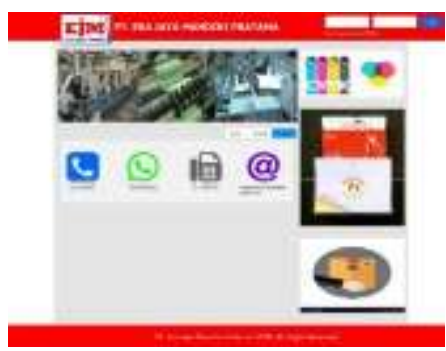

4. Halaman Member

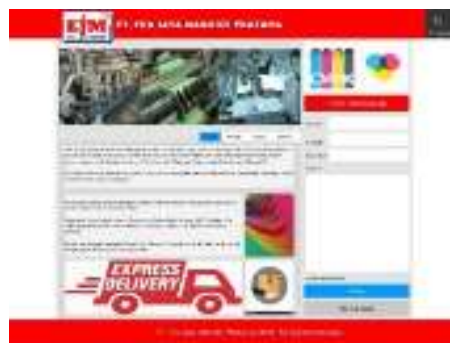

\section{KESIMPULAN}

Pada Perancangan Sistem Pemesanan Kertas Continuous Form ini dapat menjadi acuan untuk dapat diimplementasikan salah satunya dalam bentuk website dan solusi dalam meningkatkat kemudahan dalam melakuakan pemesanan dan pengelolaan data pesanan pelanggan yang lebih baik.

\section{REFERENSI}

Atningsih, Suria, Hari Sugiarto, and I Pendahuluan. 2017. "Perancangan Sistem Informasi Perpustakaan Digital Berbasis Web" 6 (4): 44 48.

Hastanti, Bambang Eka Purnama dan Indah Uly Wardati, (2015). Sistem Penjualan Berbasis Web (E-Commerce) Pada Tata Distro Kabupaten Pacitan, Jurnal Bianglala Informatika Vol 3 No 2: 1-9.

Hidayatullah, Priyanto dan Jauhari Khairul Kawistara. (2014). Pemrograman Web. Jakarta : PT. Informatika.

Hidayatun, N., Herlawati, \& Frieyadie. (2013). Aplikasi Web Untuk Sistem Informasi Akademik Sma Negeri 33 Jakarta, IX(2), 174-183.

Lukitasari, Desy, and Ahmad fali Oklilas. (2013). "Analisis Perbandingan Load Balancing Web Server Tunggal Dengan Web Server Cluster Menggunakan Linux Virtual Server.” Generic 5 (2): 31-34. http://eprints.unsri.ac.id/336/1/6.pdf.

Nofriyansyah, M. (2015). Aplikasi Monitoring Aktifitas Laboratorium Komputer, Jurnal Poli Teknik Negeri Sriwijaya : 9-29.

Pradani, Ade Jamal, Arie Wahyu Triansyah dan Annisa Utami, (2013). Pengembangan Sistem Informasi Perpustakaan Menggunakan 
Teknologi Google Web Toolkit (GWT).Jurnal Al-Azhar Indonesia

Ramanda, (2017). Sistem Informasi

Manajemen Proyek Berbasis Web, Indonesian Journal on Networking and Security : 14-17.

Rizaniar, Fani Novianti, Sardiarinto, (2015). Perancangan Sistem Informasi Wisata Air di
Daerah Istimewa Yogyakarta Berbasis Web. Evolusi Vol.III No.1 : 41-48

Simaremare, Y. P. W., Pribadi, A., \& Wibowo, R. P. (2013). Perancangan dan Pembuatan Aplikasi Manajemen Publikasi Ilmiah Berbasis Online pada Jurnal SISFO. Jurnal Teknik ITS, 2(3), 470-475. Retrieved from http://ejurnal.its.ac.id/index.php/teknik/arti cle/view/5163/1552 